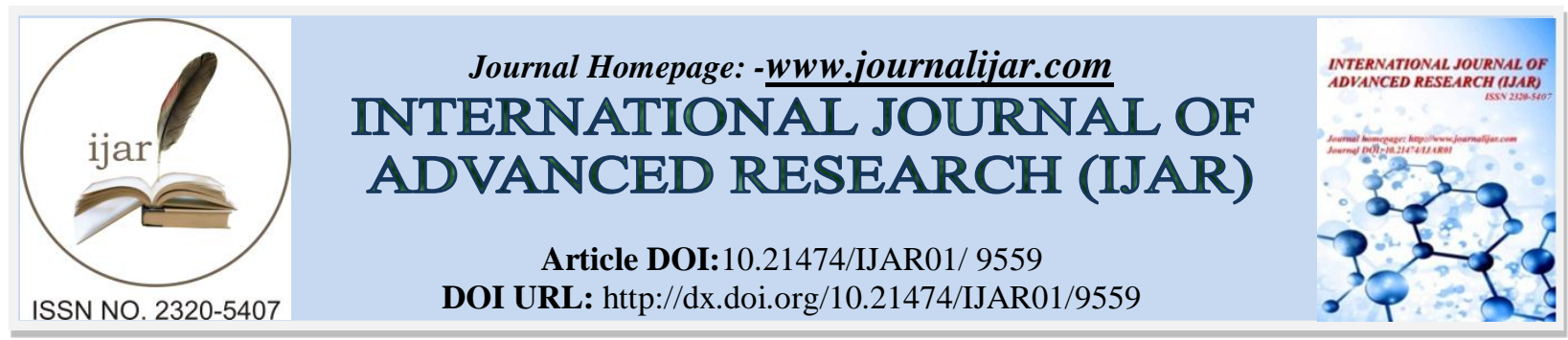

RESEARCH ARTICLE

\title{
APRON DERMATITIS: A MISDIAGNOSED ENTITY.
}

Youness Elkhachine $^{1}$ and Jalal Elbenaye ${ }^{2}$.

1. Department of dermatology, military hospital, Meknes, Morocco.

2. Faculty of medicine and pharmacy, USMBA, 30000, Fes, Morocco.

\section{Manuscript Info}

Manuscript History

Received: 08 June 2019

Final Accepted: 10 July 2019

Published: August 2019

Key words:-

apron dermatitis, dermocorticoids, local retinoids.

\begin{abstract}
We report a case of apron dermatitis observed in a 14-year-old girl, through which we put the light on this rare but misdiagnosed dermatosis which continues to pose a diagnostic and therapeutic problem despite being benign. A 14-year-old girl consulted for a 6 month little itchy rash of the hands treated unsuccessfully with 3 months of oral and topical antifungal agents. Clinical examination noted well defined erythematous plaques starting from interdigital space and involving especially palmar and lateral side of hands. Mycological exam was negative. Skin biopsy concluded to eczematous dermatitis. Final diagnosis was apron dermatitis. A slight improvement is noted by dermocorticoids application then a complete remission is obtained alternating with local retinoids. The word apron eczema was given by Calnan. It is a type of hand eczema with a distinctive topography that involves the proximal palmar aspect of two or more adjacent fingers and fanning in a semicircle over the metacarpophalangeal joints in a pattern ressembling an apron. Apron dermatitis is a rare and unrecognized disease. Physicians must be warned of this entity to avoid over treatment and diagnosis delay.
\end{abstract}

Copy Right, IJAR, 2019,. All rights reserved.

\section{Introduction:-}

We report a case of apron dermatitis observed in a 14-year-old girl, through which we put the light on this rare but misdiagnosed dermatosis which continues to pose a diagnostic and therapeutic problem despite being benign.

\section{Patient and case report:}

A 14-year-old girl consulted for a 6-month little itchy rash of the hands treated unsuccessfully with 3 months of oral and topical antifungal agents (terbinafine and fluconazole). Clinical examination noted well-defined erythematous plaques starting from interdigital space and involving especially palmar and lateral side of hands (Figure 1 and 2). Mycological exam was negative. Skin biopsy concluded to eczematous dermatitis. Final diagnosis was apron dermatitis. A slight improvement is noted by dermocorticoids application then a complete remission is obtained alternating with local retinoids.

\section{Discussion:-}

The word "apron eczema" was given by Calnan. It is a type of hand eczema with a distinctive topography that involves the proximal palmar of two or more adjacent fingers and fanning in a semicircle over the

Corresponding Author:-Youness Elkhachine.

Address:-Department of dermatology, military hospital, Meknes, Morocco. 
metacarpophalangeal joints in a pattern ressembling an apron [1]. Some authors consider it as a particular form of a dry and scaly nummular eczema of the palms. Rarely, it is caused by contact allergens, but may reflect the effect of irritants. It is more common in women and is largely endogenous in origin [2].

\section{Conclusion:-}

Apron dermatitis is a rare and unrecognized disease. Physicians must be warned of this entity to avoid over treatment and diagnosis delay.

\section{Conflict of interest:}

The Authors declare no conflict of interest.
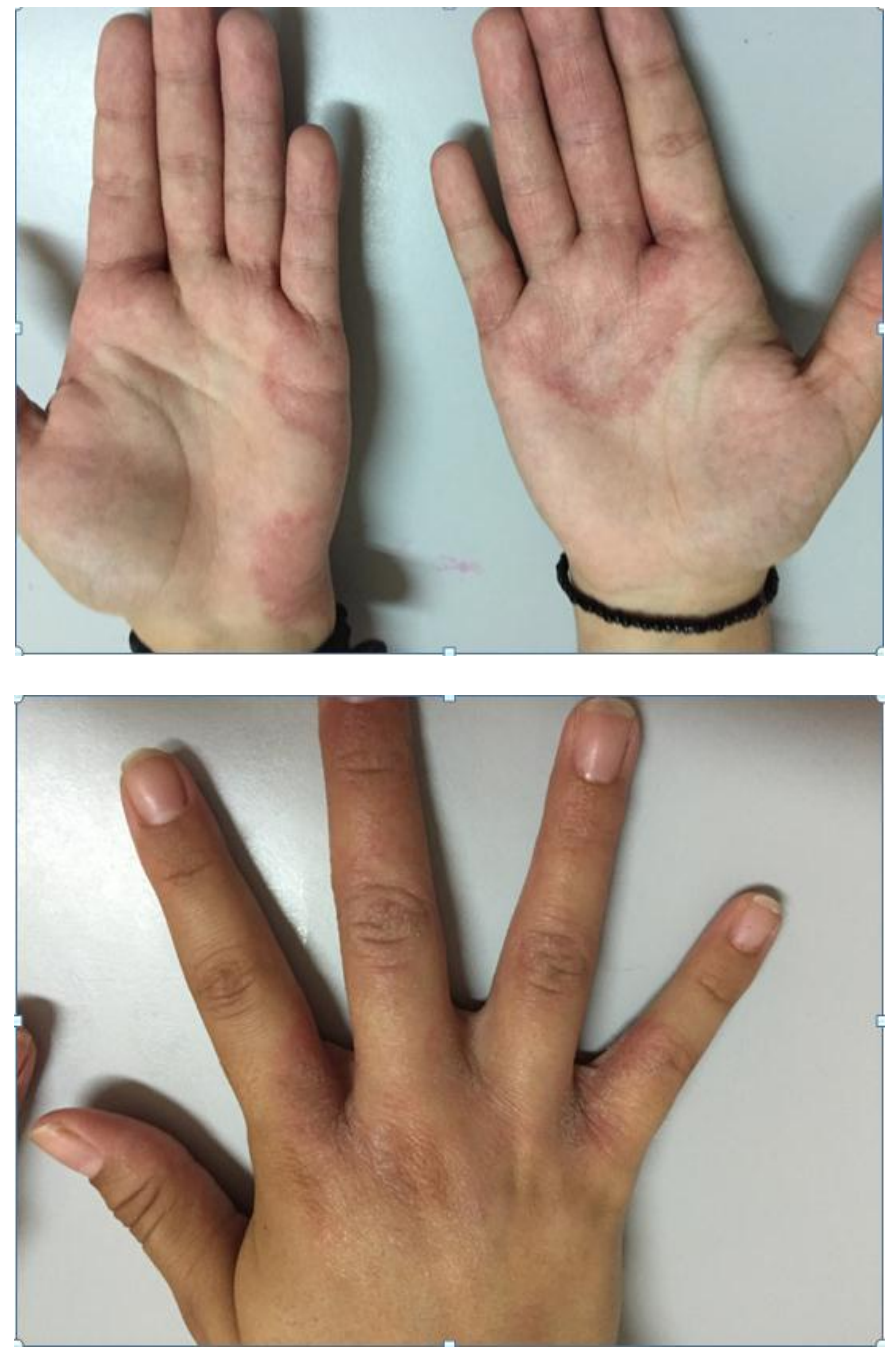

Figure 1 and 2:-erythematous well-defined plaques involving palmar and lateral side of hands.

\section{References:-}

1. Agarwal US, Besarwal RK, Gupta R, Agarwal P, Napalia S. Hand eczema. Indian J Dermatol 2014; 59: $213-$ 224.

2. Sehgal VN, Srivastava G, Aggarwal AK, Sharma AD. Hand dermatitis/eczema: current management strategy. J Dermatol 2010; 37:593-610. 